\title{
Pioneer Growth Cone Steering Decisions Mediated by Single Filopodial Contacts in situ
}

\author{
Timothy P. O'Connor, Janet S. Duerr, ${ }^{a}$ and David Bentley \\ Department of Molecular and Cell Biology, University of California, Berkeley, California 94720
}

In grasshopper embryo limb buds, the sibling Ti1 pioneers are the first neurons to initiate axonogenesis. The pioneer growth cones migrate from the limb tip to the CNS along a stereotyped route that involves a series of well-defined alterations in direction comprising discrete steering events. Filopodial exploration of the cellular terrain in the vicinity of the advancing growth cone appears to be important for steering. Some information is available on the identity of cells and cell types, on cell-surface characteristics, and on the involvement of basal lamina in these steering decisions. In the work reported here, we have used computer-enhanced fluorescence video microscopy to examine filopodial behavior and the process of growth cone migration and reorientation resulting from interactions with the normal guidance cues on the in situ substrate. We observed several different kinds of migration and steering events, which appear to be related to the absolute and relative affinities of the contacted substrates. On a relatively homogeneous substrate of intrasegmental epithelium, growth cones advance by extending veils between filopodia, as is commonly observed on uniform substrates in vitro. Where growth cones confront an orthogonal border between substrates of dissimilar affinity, they remain on the higher-affinity substrate by extending new branches along it. Subsequently, reorientation in the preferred direction on the higher-atfinity substrate is accomplished by regression of branches extended in the nonselected direction. By contrast, a single filopodial contact with a very high-affinity substrate, such as a guidepost neuron, can reorient a growth cone, even when it is migrating on a favorable substrate. In this situation, the filopodium that contacts the high-affinity substrate expands in diameter until it becomes the nascent axon.

This study addresses the question of how neurites elongate in situ, and how they alter their direction of growth in response to external guidance cues. With the advent of improved imaging techniques, high-resolution information on elongation and steering of several types of neuronal growth cones on in vitro

Received June 12, 1990; revised Aug. 16, 1990; accepted Aug. 17, 1990.

We thank David Weisblat and Corey S. Goodman for comments on these experiments and Karcn Lankford for criticizing the manuscript. Support was provided by a Canadian MRC Postdoctoral Fellowship to T.O., NIH NRSA 1 F32 NS08173 to J.S.D., and NIH Javits Award NS09074-20 and March of Dimes Birth Defects Foundation Grant 1-1089 to D.B.

Correspondence should be addressed to Dr. Timothy O'Connor, Department of Molecular and Cell Biology, Life Sciences Addition, University of California, Berkeley, CA 94720.

J.S.D. and T.O'C. contributed equally to this work.

Copyright @ 1990 Society for Neuroscience $0270-6474 / 90 / 123935-12 \$ 03.00 / 0$ substrates has been obtained (Argiro et al., 1984; Bray and Chapman, 1985; Goldberg and Burmeister, 1986, 1989; Letourneau et al., 1987; Aletta and Greene, 1988; Gregory et al., 1988; Gundersen, 1988). Generally, these growth cones appear to advance in several stages: (1) Filopodia (or microspikes), small, tubular, semirigid processes containing a core of bundled microfilaments, protrude from the leading edge. Their extension seems most likely to be driven by actin polymerization (Forscher and Smith, 1988; Mitchison and Kirschner, 1988). While filopodia can be extended without adhesion to the substratum, it scems probable that sclcctive filopodial adhesion is a normal component of growth cone advance. (2) Flat lamellar veils, devoid of organelles, then extend between neighboring filopodia. The filopodia provide a scaffold for this extension, and the placement of filopodia thus usually determines where veil extension can occur. Veil extension may occur without filopodial protrusion; in some of these cases, microfilament bundles are found within the veil (Goldberg and Burmeister, 1986), and in other cases, they are not (Kleitman and Johnson, 1989). (3) Veils then become inflated by the intrusion of organelles and other cytoplasmic material so that the body of the growth cone advances. (4) Finally, at the base of the growth cone, the tubular nascent neurite forms, probably by the bundling and stabilization of microtubules and by the release of some substrate adhesions. The precise role of tension within filopodia or veils in this sequence is presently unresolved (Bray, 1987; Letourneau et al., 1987; Aletta and Greene, 1988; Burmeister and Goldberg, 1988; Goldberg and Burmeister, 1989; Lamoureux et al., 1989).

Three basic types of steering phenomena have been observed in vitro. First, on homogeneous substrates, filopodia can protrude in several directions from the leading edge of the growth cone. Veils may extend between a subset of these, and this subset may be oriented in a new direction. Alternatively, veils may extend between filopodia in several directions, but a subset of veils may fill (Bray and Chapman, 1985; Goldberg and Burmeister, 1986). Second, particularly on a patterned substrate where there is a discontinuity between different surface coatings (Letourneau, 1975), growth cones encountering a boundary may form 2 distinct branches. The branch on the nonselected substrate is subsequently withdrawn so that steering occurs by selective branch regression (micropruning; Burmeister and Goldberg, 1988). Third, on a heterogeneous substrate, single filopodia have been observed to extend from a growth cone on a higheraffinity substrate, across a zone of lower affinity, to another region of higher affinity (Hammarback and Letourneau, 1986). The growth cone can then traverse the lower-affinity substrate along this filopodium. A similar extension along a single filopodium has been reported for a growth cone making a single filopodial contact with a glial cell in vitro (Letourneau, 1975). 
Figure 1. Schematic diagram of Til growth cone migration through $31-34 \%$ stage limb bud. The Til cell bodies lie in the tibia, and their growth cones migrate proximally across the tibia-femur $(\mathrm{Ti}-\mathrm{Fe})$ and femur-trochanter $(\mathrm{Fe}-\mathrm{Tr})$ segment boundaries before turning ventrally along the trochanter-coxa $(T r$ $C x)$ boundary. Specialized epithelial cells (represented by hexagons) to which the growth cones adhere are arrayed along these boundaries. Growth cones also interact with a series of preaxonogenesis afferent neurons (guidepost cells) located in the femur ( $\mathrm{Fel})$, trochanter $(\operatorname{Tr} 1)$, and coxa $(C x 1)$. Video sequences of growth cone behavior in regions $1-$ 4 (dashed rectangles) are shown in Figures 3 and 4.

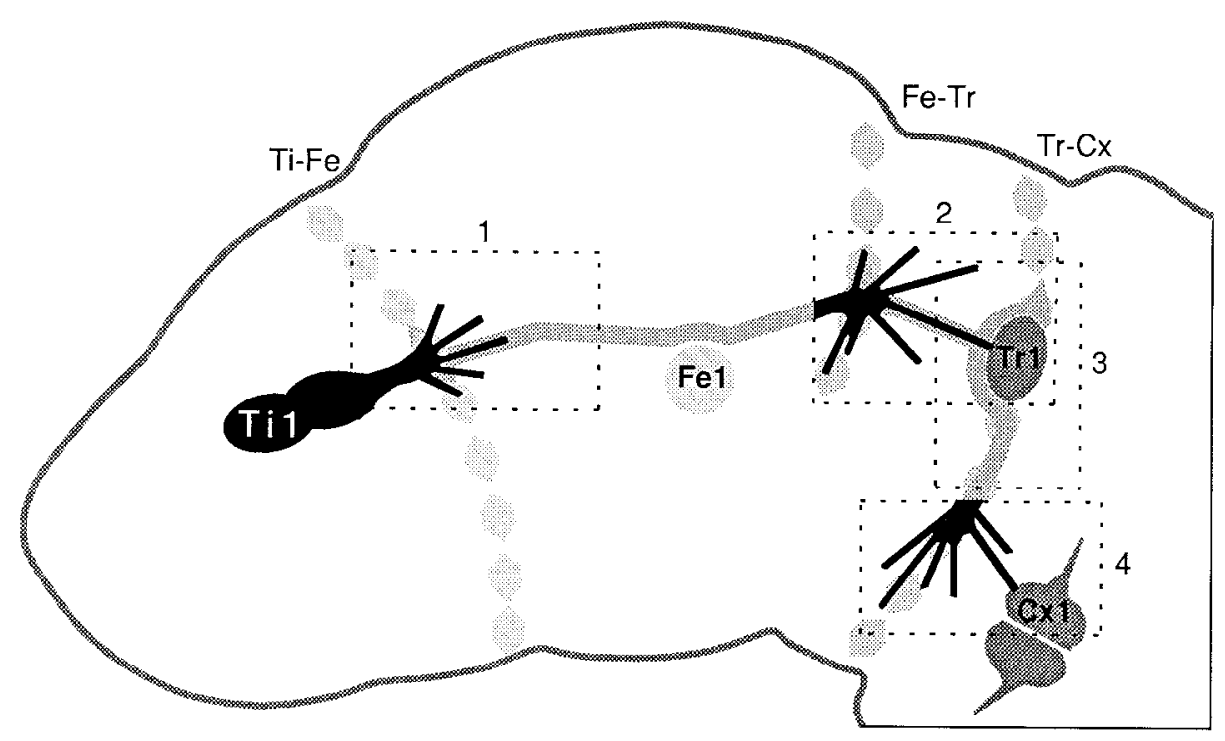

To ascertain which of these phenomena occur in situ, we have examined a pair of sibling pioneer growth cones that traverse a stereotyped pathway across several hundred microns of substrate while responding to diverse external guidance cues (Figs. 1,2 ). In the $30 \%$ stage grasshopper embryo, an epithelial mother cell at the tip of the limb bud gives rise to 2 pioneer afferent neurons (Bate, 1976). Internal cell polarity appears to be important in determining the initial site of growth cone emergence (Lefcort and Bentley, 1989). Subsequently, the growth cones migrate between a basal lamina and the basolateral plasma membrane of epithelial cells (Anderson and Tucker, 1988). Microdissection experiments and enzymatic removal of basal lamina indicate that cues adequate for growth cone migration along the normal pathway are provided by information available at the plasma membranes of the epithelial cells and nascent afferent neurons derived from the epithelium; though basal lamina is not necessary, whether it could also provide an adequate substrate has not been determined (Lefcort and Bentley, 1987; Condic and Bentley, 1989a). The epithelial cells comprise at least 2 distinct groups: intrasegmental cells and segment boundary cells (Caudy and Bentley, 1987). Within developing grasshopper limb segments (Caudy and Bentley, 1986a), and other insect epithelia (Palka, 1986; Blair and Palka, 1989), there appears to be a distal to proximal gradient or stepwise increase in substrate affinity, or other polarized guidance information. At segment boundaries, pioneer growth cones rapidly form a mechanically demonstrated adhesion with a circumferential band of specialized epithelial cells (Condic and Bentley, 1989b). Growth cone affinity for these cells is higher than for intrasegmental epithelial cells. At 3 locations along the pioneer pathway, nascent afferent (guidepost) neurons are found (Ho and Goodman, 1982; Keshishian and Bentley, 1983). Pioneer growth cones can reorient and adhere to these guidepost cells, which appear to provide a higher-affinity substrate than either type of epithelial cell (Bentley and Caudy, 1983a; Berlot and Goodman, 1984; Caudy and Bentley, 1986b). Interactions with these 3 cell types seem to account for most of the growth cone migration and steering events in the limb.

Many of the types of molecules that may be involved in insect growth-cone migration and steering appear to have vertebrate homologues (Anderson, 1988; Fessler and Fessler, 1989). These include extracellular matrix (ECM) molecules such as laminin (Fessler et al., 1987; Montell and Goodman, 1988), collagen IV (Blumberg et al., 1987), and (possibly) fibronectin (Grateios et al., 1988), as well as integrin receptors for ECM molecules (Bogaert et al., 1987), immunoglobin superfamily glycoproteins with specific homology to NCAM (fasciclin II; Harrelson and Goodman, 1988) and L1 (neuroglian; Bieber et al., 1989), and cadherins (Klambt et al., 1989). Additional molecules that do not have known vertebrate homologues, including the homophilic adhesion molecules fasciclin I and fasciclin III (Zinn et al., 1988; Elkins et al., 1990), have also been characterized. The pioneer neurons and guidepost cells express fasciclin I and may express other anti-HRP-binding cell-surface glycoproteins (Jan and Jan, 1982, Snow et al., 1987), neuroglian, amalgam (another immunoglobin superfamily protein; Seeger et al., 1988) and, in cockroaches, several antigens defined by monoclonal antibodies (Denburg, 1989).

Recent developments in techniques for image intensification, computer-image enhancement, and fluorescent labeling have made it possible to follow growth cone migration in situ in several systems (Eisen et al., 1986; Harris et al., 1987; O'Rourke and Fraser, 1989). In the work reported here, we have monitored the migration and steering of fluorescently labeled pioneer growth cones on a fillet preparation of the limb using intensified, computer-enhanced imaging (abstracted in Duerr et al., 1989; O'Connor et al., 1989).

\section{Materials and Methods}

Embryos of Schistocera americana were obtained from a colony maintained at the University of California at Berkeley. Eggs at the 30-34\% stages were sterilized and dissected in saline (Lefcort and Bentley, 1987). Embryos were transferred to a dish with a poly-L-lysine-coated glasscoverslip bottom (incubated for a minimum of $12 \mathrm{hr}$ in $5-8 \mathrm{mg} / \mathrm{ml}$ poly-L-lysine in $0.1 \mathrm{~m}$ borate buffer) containing supplemented RPMI culture medium (Condic and Bentley, 1989a) and were placed ventral side down, exposing the posterior surface of the limbs. This surface was sliced open with a glass needle and spread apart to flatten the limb epithelium. Mesodermal cells overlying the neurons were removed with a suction pipette (Lefcort and Bentley, 1987). In this "fillet" preparation, the pioneer neurons on the basal surface of the anterior limb epithelium were readily viewed with Nomarski optics (Fig. 2). Fillets were main- 

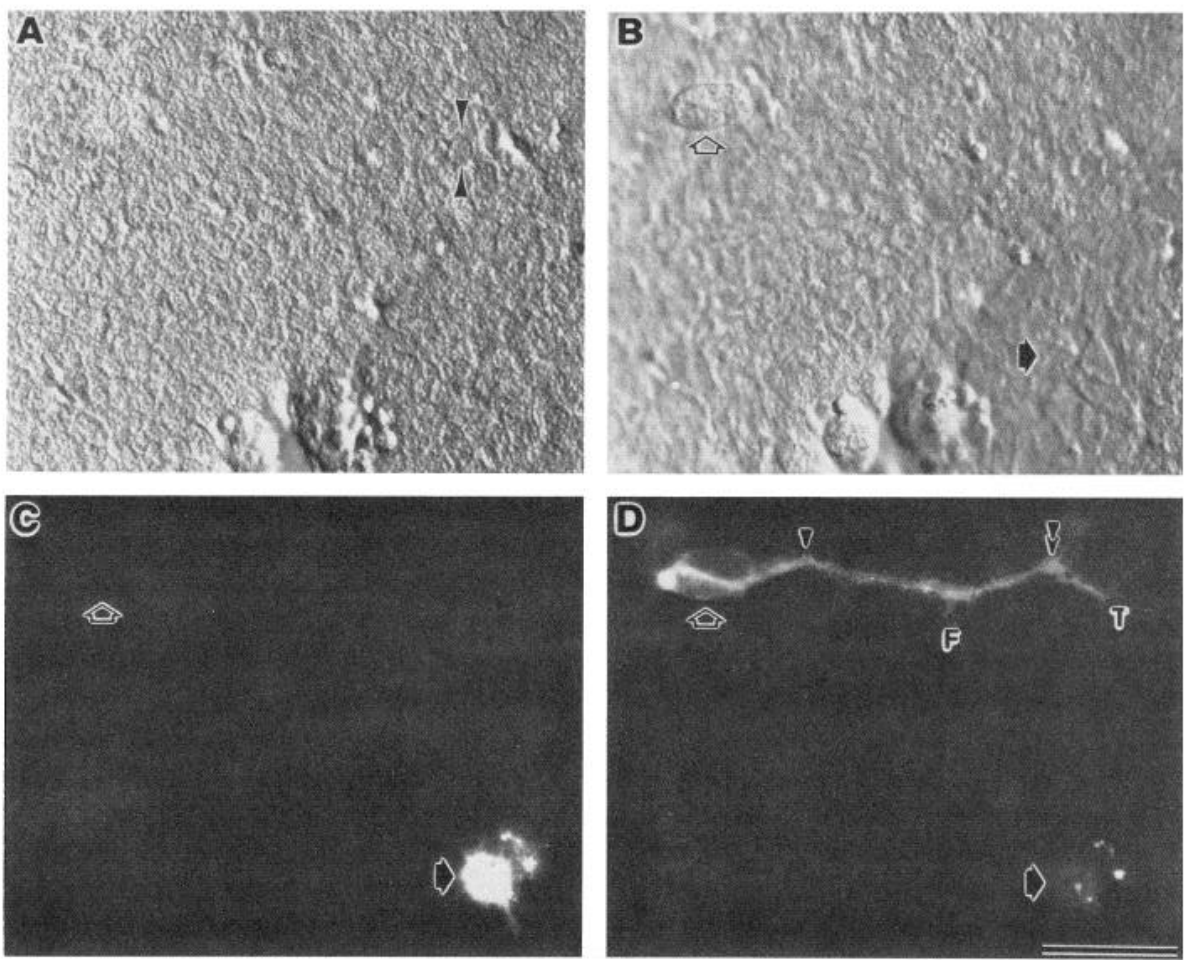

Figure 2. "Fillet" preparation of single 33\% stage limb bud that has been opened longitudinally, flattened on poly-L-lysine-coated coverslip, stripped of mesoderm, and labeled with DiI and DiO. A, The epithelial substrate, viewed in Nomarski optics, is planar and physically homogeneous. At the basal surface, no discontinuities are evident at the locations of prospective limb segment boundaries (arrowheads in $D)$. A single epithelial nucleus (which is surrounded by a thin layer of cytoplasm) lies between the arrowheads. $B$, Viewed in a slightly higher focal plane, the 2 Til pioneer cell bodies (open arrow) and the $2 \mathrm{Cx} 1$ guidepost cell bodies (solid arrow: ventral Cx1 cell) are seen apposed to the basal surface of the epithelium. $C$, The ventral $\mathrm{Cx} 1$ cell (solid arrow), labeled with $\mathrm{DiO}$, is viewed with epifluorescence. Fluorescence from the Til neurons (open arrow; labeled with DiI) is excluded with these filters. $D$, The pair of Til neurons (open arrow), labeled with DiI and viewed with epifluorescence. The nascent axons interact with the tibia-femur (single arrowhead) and femur-trochanter (double arrowhead) segment boundary epithelial cells and with the guidepost cells $\mathrm{Fel}$ (at location $F$ ) and $\operatorname{Tr} 1$ (at location $T$ ), producing a characteristic zigzag pathway. Weak fluorescence from the labeled Cx1 cell (solid arrow) is seen through these filters. Dorsal epithelium, up; proximal, right. Scale bar: $50 \mu \mathrm{m}$, for $A-D$.

tained on an inverted microscope stage at $32^{\circ} \mathrm{C}$ with an Opti-Quip infrared incubator or, for long culture periods, in a $\mathrm{CO}_{2}$ incubator. Pioneer growth cones migrated along their normal pathway, making a series of characteristic turns, on such fillets (Lefcort and Bentley, 1987).

Pioneer neurons and/or preaxonogenesis afferent (guidepost) neurons (Figs. 1, 2) were labeled with lipophilic fluorescent dyes (Honig and Hume, 1986). A glass micropipette was immersed in a suspension of $1,1^{\prime}$-dioctadecyl-3,3,3',3',-tetramethylindocarbocyanine perchlorate $\left[\mathrm{DiIC}_{18}(3)\right.$ or $\left.\mathrm{DiI}\right]$ or $1,1^{\prime}$-dihexadecyloxacarbocyanine perchlorate $\left[\mathrm{DiOC}_{16}(3)\right.$ or DiO] (Molecular Probes) and air dried. The pipette tip was then brought into contact with the cell to be labeled for 1-3 min. Dye partitioned into the plasma membrane and diffused to the growth cone in fewer than $15 \mathrm{~min}$.

Neurons were illuminated with a computer-shuttered halogen lamp and imaged through a Nikon $40 \times$ or $100 \times$ objective with a Dage 65 SIT camera. Images were processed with an Image $1 \mathrm{~A} / \mathrm{T}$ enhancement system, stored on a Panasonic TQ-2028F optical disk recorder or a LaserStor digital optical disk and photographed from a Dage 2000 video screen. In most preparations, growth cones were imaged at 2 focal planes separated by $0.5-3 \mu \mathrm{m}$ in order to include the terminations of most filopodia extended on the epithelial surface. Image sets were separated by at least $10 \mathrm{~min}$ to avoid photodamage to filopodia.

In different limb regions, the shape and area of epithelial surface explored by filopodia extending in front of the growth cone, as well as rates of filopodial elongation and growth cone translocation, were measured using Image $1 \mathrm{~A} / \mathrm{T}$ morphometric software (see Fig. 5; Tables 1, 2).

At the completion of video imaging, preparations were fixed and labeled with anti-HRP antibodies, which selectively label insect neurons (Jan and Jan, 1982; Snow et al., 1987). This labeling confirmed the placement and identity of guidepost neurons contacted by the Til growth cones (Fig. 4B), as well as the disposition of Til filopodia.
The results reported here are based on imaging of pioneer growth cones that advanced along the normal pathway in 66 limbs (in 60 embryos).

\section{Results}

\section{Growth on the fillet preparation}

The pair of Til pioneer cell bodies are located in the proximal region of the tibia (Fig. 1; throughout this text, proximal and distal refer to position with respect to the longitudinal axis of the limb). Their growth cones migrate proximally along the limb axis toward the CNS, crossing the tibia-femur and femur-trochanter segment boundaries. Within the femur, they may contact the Fel guidepost cell. At the trochanter-coxa boundary, they usually encounter cell $\operatorname{Tr} 1$, then turn ventrally along the boundary. They leave the boundary by extending to the $\mathrm{Cx} 1$ cells, then grow proximally to enter the CNS.

The fillet preparation differed from the in vivo situation by mechanical distortion of the epithelium from curved to flat (Fig. $2 A$ ), by removal of overlying mesodermal cells, by immersion in culture medium, by labeling of the cell membranes with lipophilic dyes, and by periodic illumination. Despite these changes, Til neurons grew well along their normal route. Mechanical distortion of the pathway was minimized by making the initial contact between the limb bud and the poly-L-lysinecoated substrate at the same circumferential location of the limb as the pathway. In this situation, the Til axons were not stretched 
Table 1. Mode of growth cone advance in different limb regions

\begin{tabular}{lllll} 
& \multicolumn{3}{l}{ Location } & \\
\cline { 2 - 5 } Mode & $\begin{array}{l}\text { Mid- } \\
\text { femur }\end{array}$ & $\begin{array}{l}\text { At cell } \\
\text { Tr1 }\end{array}$ & $\begin{array}{l}\mathrm{Tr}-\mathrm{Cx} \\
\text { boundary }\end{array}$ & $\begin{array}{l}\text { At cell } \\
\mathrm{Cx} 1\end{array}$ \\
\hline Veil extension & $8 / 8^{a}$ & $0 / 5$ & $10 / 10$ & $1 / 5$ \\
Filopodial dilation & $2 / 8^{b}$ & $5 / 5$ & $0 / 10$ & $4 / 5$ \\
\hline
\end{tabular}

${ }^{a}$ Eight of 8 observed growth cones migrated by veil extension in this region.

${ }^{b}$ All growth cones $(n=28)$ were observed once, except the 2 reported here; they migrated first by veil extension, then by filopodial dilation when they contacted cell Fel [see Fig. 1; this cell may or may not be differentiated when the growth cones arrive in this region (Caudy and Bentley, 1986a)].

or compressed significantly and maintained their normal zigzag path between guidance cues (Fig. $2 D$ ). Neurons that were labeled with lipophilic dye and incubated without imaging grew along the normal path to the CNS. During video imaging, Til growth cones extended in normal directions and made correct steering choices (Figs. 3, 4). We conclude that growth cone behavior with respect to local, epithelially derived guidance cues is relatively normal in this preparation.

The Til neurons are sibling cells that extend growth cones together to the CNS. In most of our preparations, both cells were labeled. In a test series, we labeled one pioneer with DiI and its sibling with DiO. We observed a range of dispositions of the 2 growth cones. At one extreme, the growth cones were almost completely separated, with one lagging up to $20 \mu \mathrm{m}$ behind the other. At the other extreme, the 2 growth cones were apposed down to the level of small branches (but not filopodia). At choice points, both growth cones typically formed similar major branches; we did not observe the 2 growth cones extending in exclusively different directions at any choice point.

As the growth cones proceeded through the limb, they encountered a diverse sequence of substrates, including the basal lamina, intrasegmental epithelial cells, segment-boundary epithelial cells, and nascent afferent neurons (guidepost cells). As these encounters occurred, growth cone morphology, rate of
Table 2. Growth cone migration parameters

\begin{tabular}{|c|c|c|c|}
\hline \multicolumn{2}{|l|}{ Filopodia } & \multicolumn{2}{|c|}{ Growth cones $(\mu \mathrm{m} / \mathrm{hr})$} \\
\hline $\begin{array}{l}\text { Distance of } \\
\text { protrusion } \\
(\mu \mathrm{m})^{a}\end{array}$ & $\begin{array}{l}\text { Rate of } \\
\text { protrusion } \\
(\mu \mathrm{m} / \mathrm{hr})\end{array}$ & $\begin{array}{l}\text { Migration by } \\
\text { veil extension }\end{array}$ & $\begin{array}{l}\text { Migration by } \\
\text { filopodial } \\
\text { dilation }\end{array}$ \\
\hline 61 & 43 & 6 & 9 \\
\hline 46 & 54 & 4 & 14 \\
\hline 52 & 54 & 2 & 8 \\
\hline 74 & 93 & 1 & 7 \\
\hline 63 & 20 & 3 & \\
\hline 59 & 5 & 3 & \\
\hline 62 & 15 & 2 & \\
\hline 46 & 31 & 3 & \\
\hline 50 & 27 & 2 & \\
\hline 63 & 26 & 9 & \\
\hline 72 & 69 & & \\
\hline $59 \pm 3^{b}$ & $40 \pm 8$ & $4 \pm 1$ & $10 \pm 2$ \\
\hline
\end{tabular}

Data points in each column are from different growth cones.

a Selected to illustrate maximum lengths.

${ }^{b}$ Mean \pm SEM.

migration, and mode of extension often changed markedly. These behaviors will be described in the order of limb regions in which they occur (Fig. 1).

\section{Region 1: growth within the femur}

The Til cell bodies are located within the tibia, close to the tibia-femur boundary (Figs. 1, 4A). They initiate axonogenesis in the proximal direction, toward the CNS, so that most of their initial migration is within the femur (Fig. 1, region 1). Guidepost ncuron Fe1, located midway through the femur, sometimes is, and sometimes is not, differentiated when the Til growth cones arrive in the midfemur.

Growth cones entering the femur typically had a small number of relatively short filopodia, which were extended predominantly in the proximal direction (within $\pm 45^{\circ}$ of the limb axis;

\footnotetext{
Figure 3. Video sequences of 3 different DiI-labeled growth cone pairs at 3 locations in 3 different limbs illustrate growth cone advance by veil extension between filopodia $(A)$ and by filopodial dilation $(B)$ and growth cone turning by selective branch regression $(C)$. $A$, In a $31 \%$ stage embryo, the pioneers initiale axonogenesis into the distal portion of the femur (Fig. 1, region 1). A relatively small number of short filopodia extend in the proximal quadrant. The growth cone advances by filling in the region between the bases of filopodia with a veil or lamellum (A2-A5, arrow). No single filopodium is followed for more than a few micrometers. Off-axis veils and branches arise (A5) but are eventually withdrawn. Interframe intervals, in min: $43,52,45,109 . B I$, In a $32.5 \%$ stage limb, the pioneer growth cones are at the femur-trochanter segment boundary (double arrowhead; Fig. 1, region 2) and are extending a major branch ventrally. Two filopodia (arrow, arrowhead) extend proximally. B2, The dorsal filopodium (arrow) contacts cell Tr1 ( $T$; confirmed by subsequent anti-HRP labeling; cf. Fig. $4 B)$. It begins to extend secondary filopodia along the cell surface and to increase in diameter in several locations along its shaft. $B 3$, The dorsal filopodium (now branch) displays a characteristic palmate configuration on the $\operatorname{Tr} 1$ surface and continues to increase in diameter. B4, Filopodia extend ventrally along the trochanter-coxa boundary (large arrowheads) from the branch formed by the dorsal filopodium. The major branch (white arrow), which originally extended ventrally along the femur-trochanter boundary, is in the process of withdrawal. B5. The original dorsal filopodium has become enlarged to the size of an axon, which is now straighter than the filopodium. The original ventral branch at the femur-trochanter boundary is withdrawn. The ventral filopodium (arrowhead), also contacting cell Tr1, has also enlarged to the size of an axon. (Nlthough both growth cones were labeled, the possibility that these 2 filopodia each were from a different member of the pair of growth cones would be most consistent with our observations of single labeled growth cones.) Interframe intervals, in min: 88, 34, 57, 169. $C 1$, In a 33\% stage limb, prominent proximal $(p)$ and dorsal $(d)$ branches from the pioneer growth cones extend across the Trl cell to the trochanter-coxa boundary (Fig. 1, region 3). A small ventral protrusion (v) is emerging behind several short filopodia. $C 2$, The proximal branch $(p)$ is almost withdrawn, and the ventral protrusion $(v)$ is enlarging. $C 3$, The ventral protrusion $(v)$ has become a branch, which is elongating by veil extension between numerous short filopodia (white arrow). $C 4$, Dorsal and ventral branches are now equal in length and extend on opposite sides of cell $\operatorname{Trl}(T$; arrowheads; trochanter-coxa boundary). The ventral branch is elongating by extending lamellae between filopodia (white arrow). $C 5$, The dorsal branch $(d)$ has almost completely withdrawn, and the growth cones are committed to the ventral turn. They continue to advance by veil extension between short filopodia (white arrow). Several lengthy filopodia (arrowheads) are advancing ventrally; the left-most of these have emerged from the nascent axon well behind the leading edge of the growth cones. Interframe intervals, in min: 24, 22, 104, 56. Scale bars, $10 \mu \mathrm{m}$. Dorsal epithelium, up; proximal, right (all frames).
} 

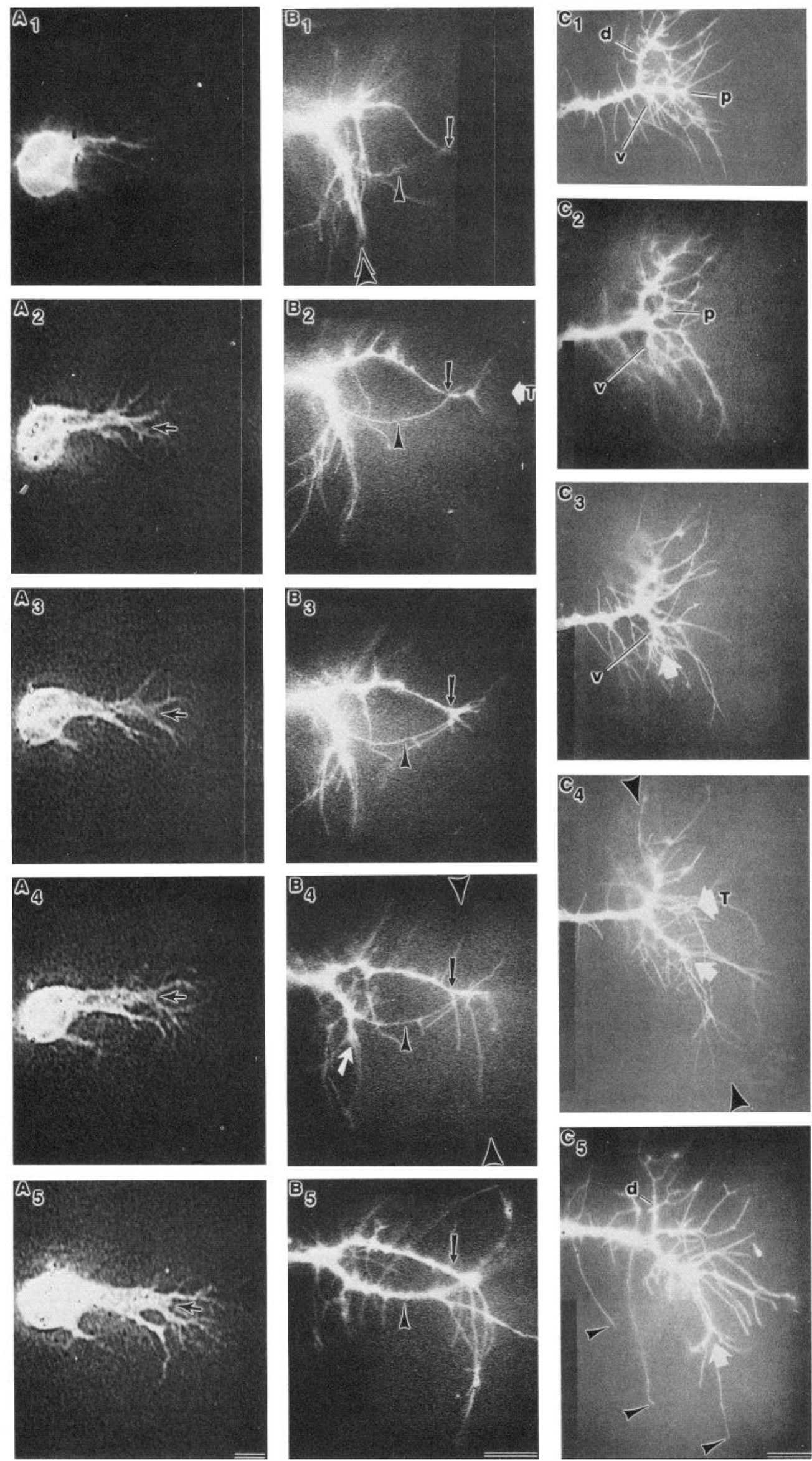
Figure 4. Growth cones' reorientation from trochanter-coxa segment boundary to $\mathrm{Cx} 1$ guidepost cells (Fig. 1 , region 4 ) at $34 \%$ stage. $A$, A fixed, control, anti-HRP labeled intact limb where the Til growth cones extended proximally to contact cell $\operatorname{Tr} 1(T)$, turned ventrally along the trochantercoxa boundary (between triangles), and contacted the Cxl cells $(C)$ with a prominant, enlarged-appearing filopodium (arrow; from Caudy and Bentley, 1987; reversed negative). $B$, At a higher magnification, growth cones fixed and labeled with anti-HRP antibody after the turning event followed in frames $C$ $F$ have contacted cell $\operatorname{Trl}(T)$, turned ventrally along the segment boundary, and crossed (arrow) to the $\mathrm{Cx} 1$ cells $(C)$. $C-F$ show high and low magnification images of the same growth cones before and after the turn to the $C x 1$ cells. $C$, The same pioneer neurons labeled with DiI at an earlier stage where the growth cones $(g c)$ are migrating ventrally along the trochanter-coxa boundary (triangles). At the femur-trochanter boundary (double arrowhead), the nascent axons are reoriented toward cell $\operatorname{Tr} 1(T$; see also $B)$. The $C x 1$ cells $(C)$ have been marked with a crystal of DiI. $D$, After $193 \mathrm{~min}$, the nascent axons (arrow) can been seen leaving the boundary and crossing to the $\mathrm{Cx} 1$ cells. $E$, Imaged with a $100 \times$ objective, the growth cones in $C$ can be seen to extend a single filopodium (arrow) to the $\mathrm{Cx} 1$ cells. $F$, By expanding its diameter, the filopodium from $E$ becomes converted to the axon seen in $D$. Dorsal epithelium, $u p$; proximal, right. Scale bars, $A, C, D, 50 \mu \mathrm{m}$; $B, 25 \mu \mathrm{m} ; E, F, 10 \mu \mathrm{m}$.
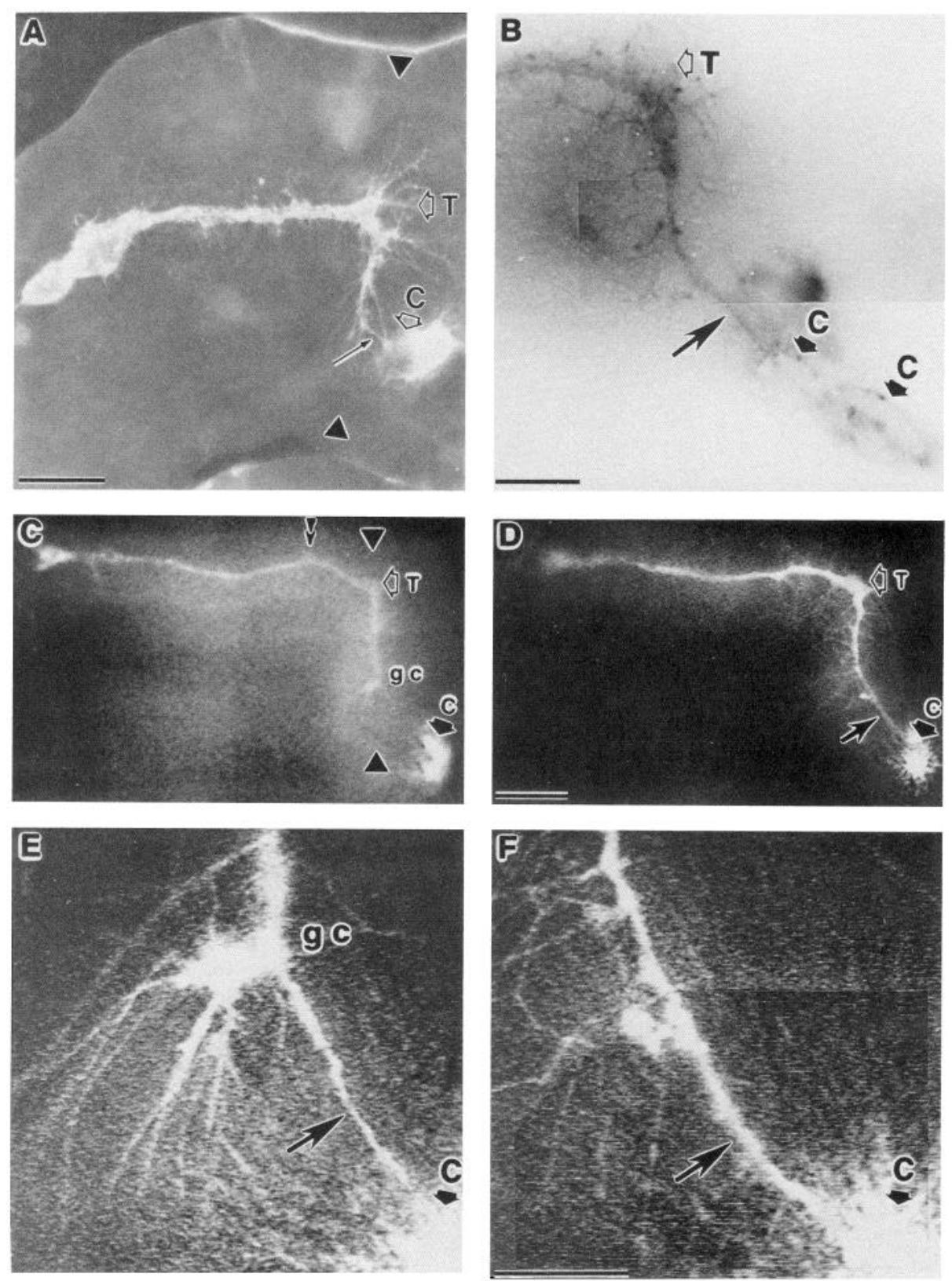

Fig. 3A). Most filopodia were in the plane of the basolateral epithelium, though some extended into the interstices between epithelial cells or away from the epithelium. Growth cones in the femur extended filopodia over regions that were about equal in length and width (Fig. $5 B$ ) and encompassed an area on the epithelial surface of approximately $500 \mu \mathrm{m}^{2}$ (Fig. $5 A$ ). In this region, we monitored 8 pairs of growth cones where we were able to observe the details of how the growth cone advanced over the substrate (Table 1). All 8 of these growth cones advanced by extending flat lamellae or veils into the space between the bases of filopodia (Fig. $3 A$ ). The growth cones advanced in small increments and did not follow the route of any particular filopodium for more than a few micrometers. We refer to this mode of advance as veil extension (Fig. $6 A$ ). Growth cones advanced by veil extension at an average rate of $4 \mu \mathrm{m} / \mathrm{hr}$ (Table 2).
Growth cones proceeded through the femur without major deviation from the proximal, axial route. As they migrated, filopodia, veils, and short branches were extended in off-axis directions (Fig. 3, A5). These veils and branches did not continue to extend and were eventually withdrawn. Thus, the axial course was achieved by preferential elongation of more proximally oriented branches. This steering process can be viewed as a series of shallow-angle turns (Fig. $6 \mathrm{~A}$ ).

Til axons characteristically have a turn toward cell Fe1 in the midfemur (Figs. 1, 2D, 4C). This configuration appeared to be generated by 2 different mechanisms, depending upon whether or not Fel was differentiated when the growth cones arrived in its vicinity. During their migration, 2 of the 8 growth cones observed in this region made filopodial contact with a differentiated $\mathrm{Fe}$ l. These growth cones reoriented toward $\mathrm{Fe} 1$ by filopodial dilation (discussed in more detail below). When Fel 


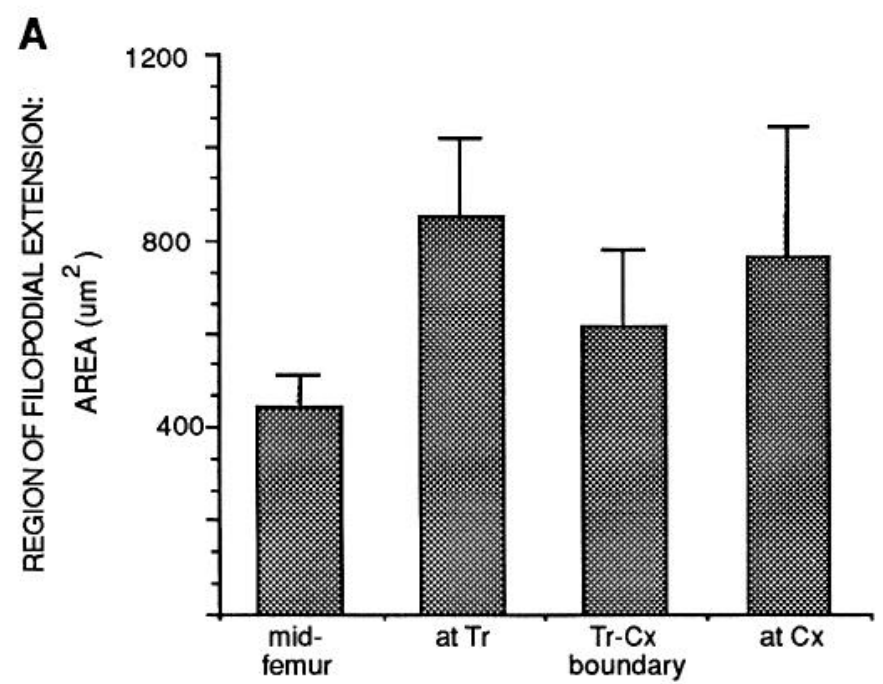

GROWTH CONE LOCATION

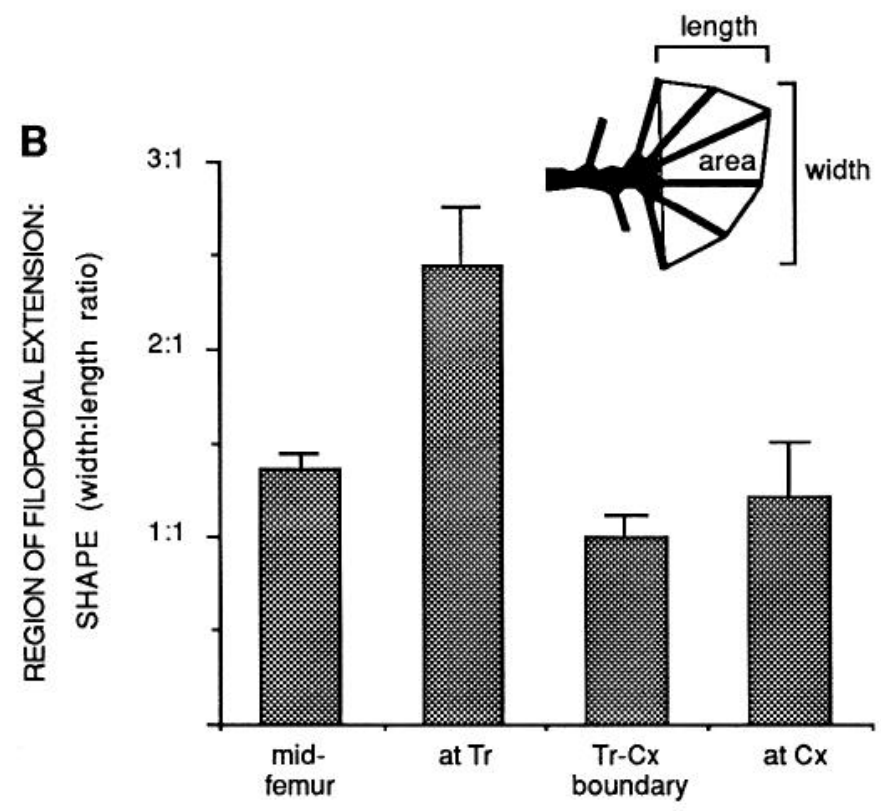

GROWTH CONE LOCATION

Figure 5. Sizes $(A)$ and shapes $(B)$ of areas of filopodial extension measured as indicated on inset for growth cones in different limb regions. Growth cones are (1) in the femur but not in contact with cell Tr1 (midfemur; $n=24$ ); (2) on cell $\operatorname{Tr} 1$ and extending filopodia dorsally, ventrally, and proximally ( $a t \operatorname{Tr} I ; n=11$ ); (3) migrating ventrally along the trochanter-coxa boundary ( $T r-C x$ boundary; $n=7)$; or (4) have established the first filopodial contact with the Cxl cells (at $C x 1 ; n=$ 7). The shape of the region explored by filopodia extended from growth cones at $T r$ is significantly different from shapes in other regions at the 0.01 level (1-way ANOVA). Bars indicate SEM.

had not differentiated, the growth cones migrated past this location without reorienting (Fig. $4 A$ ). In one such case, small ventral branches directed toward Fel developed secondarily in the midfemur and appeared to laterally displace the Til axon toward $\mathrm{Fe}$. This phenomenon would secondarily create an axon reorientation at $\mathrm{Fel}$.
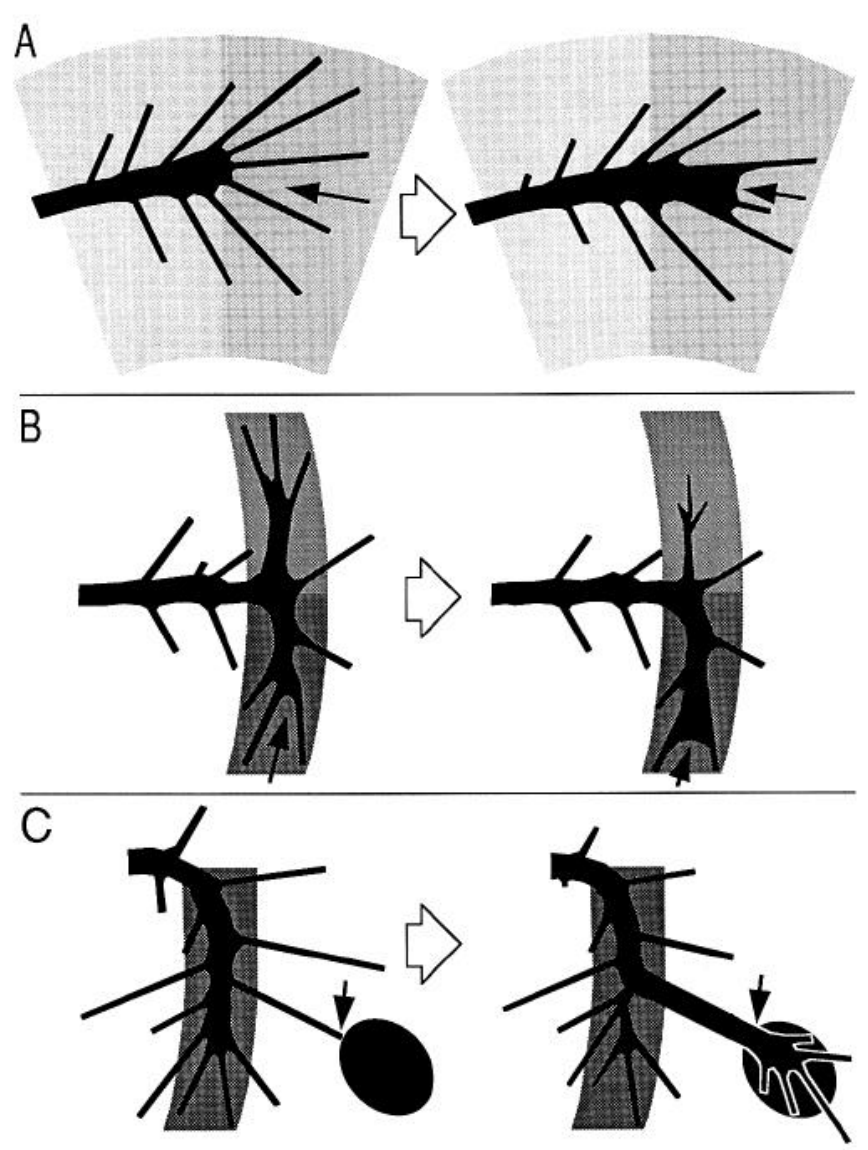

Figure 6. Diagrammatic representation of pioneer growth cone migration and steering events on in situ substrates. $A$, Within the femur, the growth cones migrate between the basal lamina and the surfaces of epithelial cells. This substrate appears to be relatively homogeneous with a proximal gradient or weak step increase in affinity (see Discussion). Growth cones advance by filling in flat veils between filopodia (veil extension) and do not advance along any particular filopodium for more than a few micrometers. Steering occurs by shallow angle turns along more proximally oriented filopodia, veils, or branches. $B$. At the trochanter-coxa boundary, growth cones encounter an orthogonal band of segment-boundary cells, which represent a sharp discontinuity in substrate adhesivity. This adhesivity may increase ventrally. Growth cones usually extend major branches in both directions, with the ventral branch eventually being followed and the dorsal branch withdrawn. On the segment-boundary cells, the growth cone branches advance by veil extension. $C$, At 3 locations in the limb, growth cones migrating on intrasegmental epithelial cells or on segment boundary cells encounter preaxonogenesis (guidepost) neurons. Single filopodial contacts with any of these cells can abruptly reorient the growth cone. The steering event occurs by increase in the diameter of the filopodium until it becomes a nascent axon (filopodial dilation).

\section{Region 2: orientation to guidepost cell $\operatorname{Tr} 1$}

Upon crossing the femur-trochanter boundary, Til growth cones usually grow directly into contact with the $\operatorname{Tr} 1$ guidepost cell, which lies on the distal side of the trochanter-coxa boundary (Figs. 1, region 2; $4 B$ ). Sometimes this requires no reorientation of the growth cone trajectory (Fig. $4 A$ ), but more often, an abrupt shallow angle turn toward $\operatorname{Tr} 1$ occurs from a distance of about $30 \mu \mathrm{m}$ (Figs. $2 D, 4 C$; Caudy and Bentley, 1986b). Observation of fixed tissue has suggested that these turns might be mediated by single filopodial contacts (Caudy and Bentley, 1986b), and the video data confirm that this is the case. When a single 
Figure 7. Selective elongation and reorientation of individual filopodia. $A$, From a growth cone spreading on cell $\operatorname{Tr} 1$ at the trochanter-coxa boundary, a filopodium (open arrows) was observed first to elongate proximally, then to reorient its tip and continue to elongate along an orthogonal, circumferential route. This location (white arrow) may correspond to a circumferential band of specialized segment boundary cells. $B$, A similar filopodial configuration in a different embryo. $C$, In an intact limb, fixed and labeled with antiHRP antibodies, a filopodium (open arrow) from a Til neuron and a filopodium (black arrow) from a $\mathrm{Cx} 1$ cell extend along the same circumferential route (white arrow). The filopodium from the $\mathrm{Cx} 1$ cell is much longer than any other Cx1 filopodia, except for a filopodium (arrowhead) extended along the route the $\mathrm{Cx} 1$ growth cones will take to the CNS. $D$, In a live fillet preparation where both the Til growth cones and the Cxl cells were labeled with DiI, a Til filopodium (open arrow) and a Cx1 filopodium (black arrow) were observed to elongate toward each other along the same circumferential route (white arrow). Again, Cx1 filopodia extending along this route were much longer than filopodia extended in other directions. Scale bars, $10 \mu \mathrm{m}$. Dorsal epithelium, up; proximal, right.
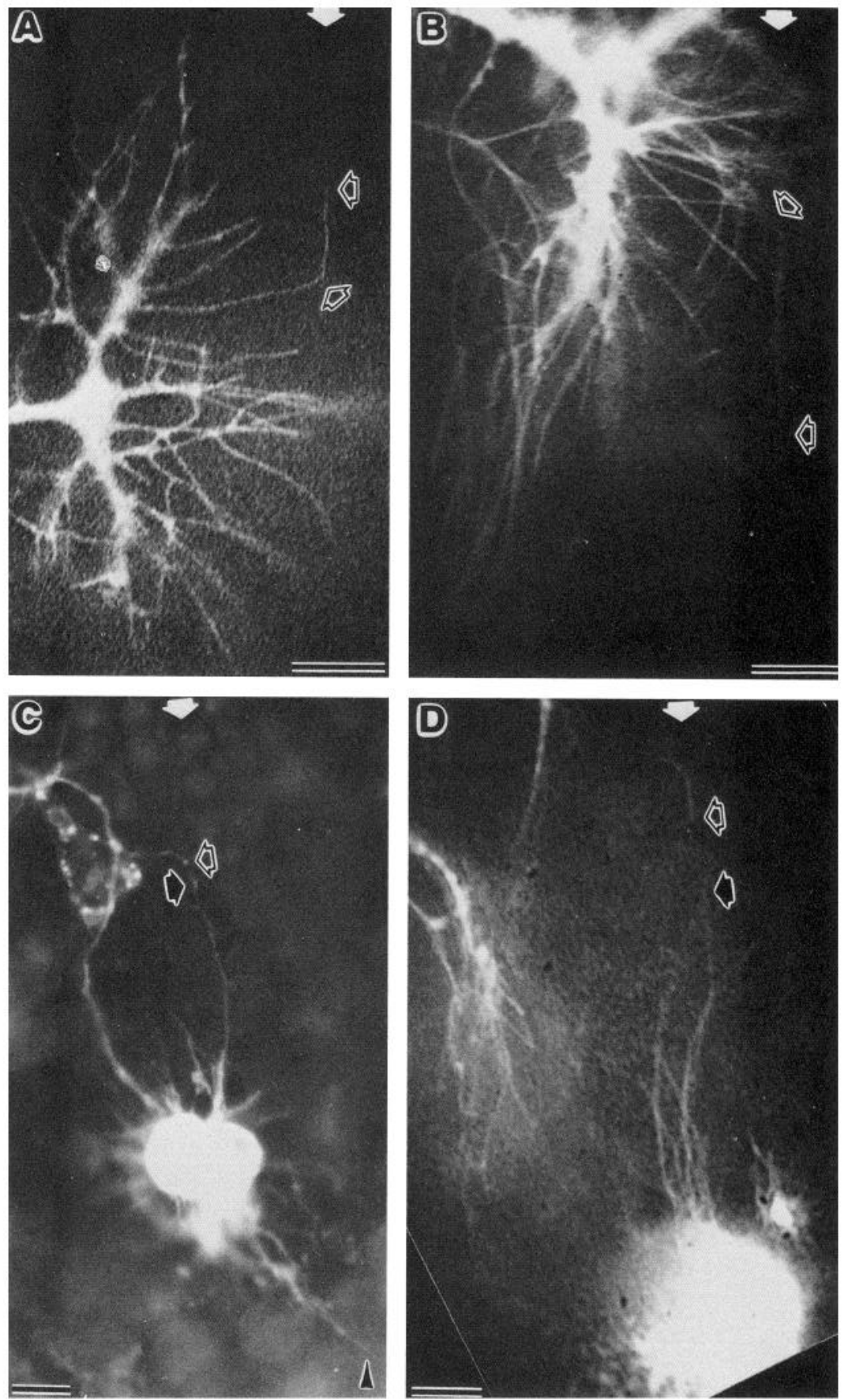

filopodium contacts $\operatorname{Tr} 1$, it begins to increase in diameter (Fig. $3 B$ ). Often, this initial increase is not uniform along the length of the filopodium. Frequently, the tip begins to expand into a palmate configuration, from which secondary filopodia will subsequently emerge (Fig. 3, B3). The shaft between the palmate region and the growth cone may remain quite narrow while discontinuous segments of the filopodium begin to dilate (Fig. 3 , B2). This increase in caliber continues until the filopodium is converted into a substantial branch, then eventually into an axon. As the filopodium becomes converted into a branch, the branch frequently also becomes straighter (Fig. 3, B1-3, B5). By this process of increase in filopodial caliber, the position of the growth cone advances from the base of the selected filopodium to its tip in a single saltation. We will refer to this mechanism of growth cone advance as filopodial dilation. Of 5 growth cone pairs approaching cell $\operatorname{Tr} 1$ where we could determine the mode of migration, all 5 advanced by dilation of single filopodia that contacted $\operatorname{Tr} 1$ (Table 1). The average rate of growth cone migration by filopodial dilation was about $10 \mu \mathrm{m} / \mathrm{hr}$ (Table 2).

Even when the growth cone had a major branch extending in a different direction, a filopodial contact with cell $\operatorname{Tr} 1$ would reorient the growth cone. During the dilation of the filopodium 
contacting $\operatorname{Tr} 1$, the nonselected branch and filopodia protruding from it could remain extended (Fig. 3, B2). The branch and its filopodia were eventually withdrawn (Fig. 3, B4).

\section{Region 3: orientation along the trochanter-coxa boundary}

The Til growth cones make a ventral turn at the trochantercoxa boundary (Figs. 1, region $3 ; 4 C$ ). In the intact limb, this boundary is marked by the location of cell $\operatorname{Tr} 1$ and by an inflection in the curvature of the apical surface of the epithelium (Caudy and Bentley, 1986b). In the fillet, the boundary can often be identified by a linear discontinuity in the contact between the apical epithelial surface and the coverslip, but no discontinuity is evident at the basal surface of the epithelium (Fig. $2 A, B)$. Following observation of growth cone turning, the location of the boundary was confirmed by anti-HRP labeling of Tr1 (Fig. 4B)

At cell $\operatorname{Tr} 1$, various degrees of branching and spreading of lamellae on the cell surface were seen. These morphologies appeared to be related to the degree of differentiation of $\operatorname{Tr} 1$, as judged by the intensity of subsequent anti-HRP labeling (Fig. $4 B$ ). Upon encountering the boundary (usually at the circumferential location of $\operatorname{Tr} 1$ ), growth cones extended filopodia into the distal region of the coxa, but branches did not enter the coxa (Figs. 3, C1; 4A). Lengthy filopodia were extended both dorsally and ventrally so that the filopodial array had the greatest ratio of width to length at this location (Fig. $5 B$ ), and also extended over the largest area of epithelial surface (about $900 \mu \mathrm{m}^{2}$; Fig. $5 A$ ). Typically, new branches of approximately equal size began to extend both dorsally and ventrally along the limb circumference (Figs. 3, C4; 7A). Labeling of single Ti1 neurons showed that individual growth cones could have both dorsal and ventral branches. Either the dorsal or the ventral branch could appear first. Eventually, the ventral branch increased in both length and diameter and became selected for continued axon outgrowth (Fig. 6B). The dorsal branch could grow at least $20-30 \mu \mathrm{m}$ (Fig. 3, C2), but was always withdrawn (Fig. 3, C5). Occasionally, growth cones would encounter the boundary ventral to the location of cell $\operatorname{Tr} 1$. These growth cones responded similarly to the boundary and proceeded along a ventral branch.

Branches migrating along the boundary elongated by veil extension. Numerous, often lengthy, filopodia were extended along the boundary, but the growth cone changed position by spreading lamellae between the bases of filopodia, and no particular filopodium dilated (Fig. 3, C3). Of 10 growth cones where we could monitor the details of positional change in this location, all advanced by veil extension (Table 1 ).

\section{Region 4: orientation to the CXI guidepost cells}

$\mathrm{Ti} 1$ growth cones leave the trochanter-coxa boundary and reorient proximally toward the CNS by contacting the $2 \mathrm{Cx} 1$ guidepost cells (Figs. 1, region 4; 4; Bentley and Caudy, 1983b). Observation of growth cones fixed in situ suggested that this steering event could be mediated by single filopodia (Fig. $4 A$; Caudy and Bentley, 1986b). We observed 5 growth cone pairs make this turn. In 2 cases, a single filopodium that established contact with a Cx1 cell dilated into an axon (Fig. $4 C-F$ ). In 2 cases, 2-4 filopodia that each contacted a $\mathrm{Cx} 1$ cell at about the same time each expanded into a small branch. These small branches then fused into an axon. In contrast, filopodia that contacted the $\mathrm{Cx} 1$ cell after this process of branch expansion began did not become branches and could be retracted. In the fifth case, several filopodia contacted the $\mathrm{Cxl}$ cell at about the same time, and the growth concs crossed to the $\mathrm{Cx} 1$ cclls by veil extension between these filopodia. These results indicate that, as is the case with cell $\operatorname{Tr} 1$, a single filopodial contact with a Cxl cell can reorient the growth cone by filopodial dilation. This reorientation can occur while other filopodia, or branches, remain extended along the trochanter-coxa boundary (Fig. $4 E$ ).

\section{Behavior of fllopodia}

An objective of this work was to monitor the full disposition of individual filopodia from these identified growth cones. In well-labeled growth cones, processes were observed that were (1) less than $0.25 \mu \mathrm{m}$ in apparent diameter, (2) uniform in diameter from tip to base, (3) uniform in labeling brightness from tip to base, and (4) terminated abruptly without a pretip change in diameter or brightness (Fig. 3, C5). These appear to be filopodia that have been labeled to their tips.

Filopodia varied in length from a few micrometers to over $70 \mu \mathrm{m}$. Growth cones in most locations on the limb epithelium had numerous filopodia in the $10-30-\mu \mathrm{m}$ range (Figs. 3, C5; $4 E$; $7 A$ ), but filopodia over $50 \mu \mathrm{m}$ in length were regularly observed (Table 2). In addition to arising from the leading edges of growth cones, filopodia also emerged from the nascent axon shaft distal to the growth cone (Fig. 3, C4, C5). Because the Til growth cones migrated relatively slowly, imaging at intervals of $15 \mathrm{~min}$ or longer proved adequate to follow individual filopodia, though maximum rates of extension and retraction may not have been recorded at these intervals. Rates of protrusion of a set of filopodia of various lengths averaged about $40 \mu \mathrm{m} / \mathrm{hr}$ (Table 2). Similar rates of retraction were observed. Individual filopodia could persist for over $1 \mathrm{hr}$. Filopodia initially extended from the leading edge of the growth cone maintained their position with respect to the epithelium as the growth cone continued to extend. Persistent filopodia could remain extended until their site of origin became part of the axon. While the growth cone proceeded in the selected direction, filopodia could remain extended in nonselected directions.

Individual filopodia could make marked changes in course as they extended. From growth cones at the trochanter-coxa segment boundary, filopodia were observed that first extended proximally, then turned onto a circumferential pathway (Figs. $7 A, B, 8)$. The tips of these filopodia were observed to change course (rather than a bend occurring secondarily along an extended filopodium). These filopodia appeared to be reoriented by external guidance features. Filopodia from 2 different neurons could grow toward each other with a high degree of spatial precision (Figs. $7 C, D, 8$ ). In such cases, both filopodia may have been oriented by the same external guidance cue. Among radial filopodia extended from a neuron, those filopodia that extended at specific circumferential locations often protruded for much greater distances than filopodia extended in other directions (Fig. 7C,D).

\section{Discussion}

To compare growth cone elongation and steering mechanisms in situ with those that have been observed in vitro, we have monitored identified growth cones as they encounter a series of described cellular guidance features on an epithelial "fillet" preparation. In vitro, most growth cones advance by projecting filopodia from their leading edge, extending flat, organelle-free veils between the filopodia and selectively expanding veils to accommodate the material in the body of the growth cone (Bray and Chapman, 1985; Goldberg and Burmeister, 1986; Letour- 


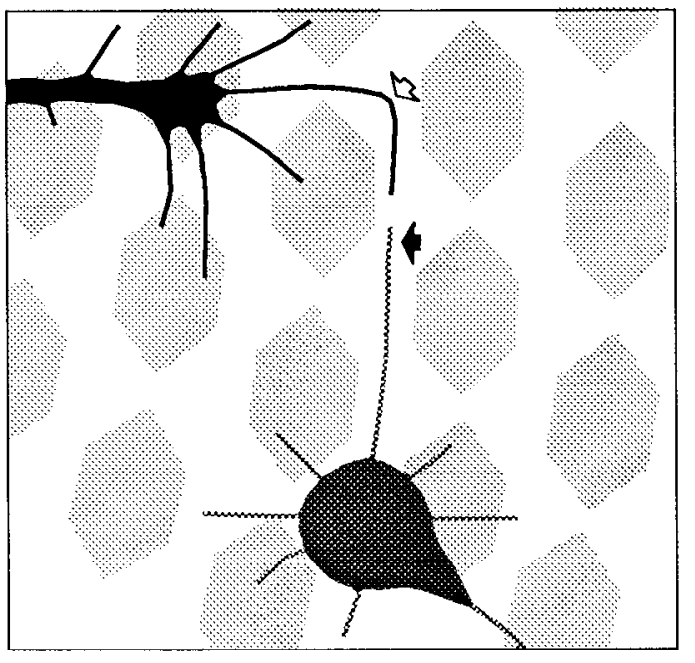

Figure 8. Schematic diagram of selective behavior of filopodia obscrved on limb epithelium. Individual filopodia can reorient sharply (open arrow) during protrusion, possibly along guidance substrates such as circumferentially arrayed epithelial cells. When filopodia are radially protruded from preaxonogenesis neurons, those that extend at certain locations (near limb segment boundaries or on the growth cone route to the CNS) frequently become much longer (solid arrow) than other filopodia. These behaviors indicate that extension of a filopodium is not a ballistic event and can be altered by substrates encountered by the tip of the filopodium.

neau et al., 1987; Aletta and Greene, 1988; Mitchison and Kirschner, 1988). We observed that this is the mechanism of growth cone migration along a substantial portion of the pioneer pathway. Pioneer neuron axonogenesis commences with the projection of filopodia proximally along the limb axis from the tibia into the distal region of the femur, followed by extension of veils between selected filopodia and the subsequent conversion of filled veils to tubular nascent neurite. Growth cone migration by veil extension is also the mechanism of ventral elongation on the trochanter-coxa segment boundary. Within the femur and along the segment boundary, growth cones are thought to be migrating along a fairly homogeneous substrate where differences in substrate affinity between the leading edge of the growth cone and the tips of filopodia projected along the path of migration would be gradual or small (Bentley and Caudy, 1983a; Berlot and Goodman, 1984; Caudy and Bentley, 1986a). Thus, elongation by veil extension may be a characteristic form of growth cone migration on relatively homogeneous substrates in situ, as in vitro.

Growth cone migration in several limb regions occurred by a different mechanism: a single filopodium dilated to become the nascent neurite. Expansion of the filopodium often occurred first at the tip, then at locations along the shaft. The growth cone advanced in a saltation equal to the length of the filopodium. Migration by filopodial dilation was observed at the 3 locations in the limb where the tip of a filopodium has contacted a nascent afferent (guidepost) neuron. Examination of pioneer neurons fixed in situ in intact limbs first suggested that growth cone reorientations along single filopodia could occur: single filopodia that were contacting guidepost cells and that appeared, in different embryos, to be in successive stages of dilation were observed. Also, nascent axons often had a zigzag configuration of short segments that were oriented toward guidepost cells and that were about the length of average filopodia (Caudy and
Bentley, 1986b). Pioneer growth cones extend many filopodia and lamellae on the surfaces of guidepost cells (Caudy and Bentley, 1986b) and rapidly adhere to them (Condic and Bentley, 1989a). This cell-cell affinity may be partially mediated by the homophilic adhesion glycoprotein fasciclin I (Elkins et al., 1990), which is expressed by both cell types. In vitro, elongation of chick dorsal root ganglion growth cones along a single filopodium has been observed where a filopodium protruded from a growth cone on a relatively high-affinity substrate projected across a strip of lower affinity to contact another region of high affinity (Hammarback and Letourneau, 1986). Elongation along a single filopodium has also been observed in at least 1 case where a filopodium from a chick DRG growth cone migrating on a polyL-lysine-coated substrate contacted an isolated glial cell (Letourneau, 1975). Elongation by filopodial dilation may therefore occur where there is substantial heterogeneity between the substrate at the leading edge of the growth cone and at the tip of the dilating filopodium.

In the electron microscrope, microtubules and organelles have been observed aligned along microfilament bundles extending into the growth cone from filopodia (Letourneau, 1979; Tosney and Wessells, 1983). In some cases, veils appear to begin filling by the advance of material along presumed microfilament-bundle "ribs" extending into veils from filopodia (Goldberg and Burmeister, 1986). Thus, microfilament bundles may provide a track that, by tension or other signaling mechanisms, mediates the forward translocation of microtubules and organelles. Where growth cones advance directly by filopodial dilation, rather than veil extension, this process may be greatly facilitated.

On the fillet preparation, pioneer growth cones migrated at about $4 \mu \mathrm{m} / \mathrm{hr}$ by veil extension and about $10 \mu \mathrm{m} / \mathrm{hr}$ by filopodial dilation (Table 2). In ovo, these growth cones traverse their $400-\mu \mathrm{m}$ pathway in about $24 \mathrm{hr}$, a substantially faster average rate of about $17 \mu \mathrm{m} / \mathrm{hr}$ (Caudy and Bentley, 1986b). These rates are moderately slow when compared to those of a variety of other growth cones, including, for example, leech ganglionic axons in vivo $(5 \mu \mathrm{m} / \mathrm{hr}$; Braun and Stent, 1989), rat superior cervical ganglion neurites on collagen (embryonic, 8$22 \mu \mathrm{m} / \mathrm{hr}$; adult, $4-13 \mu \mathrm{m} / \mathrm{hr}$; Argiro et al., 1984), PC12 cells on poly-L-lysine and collagen $(20 \mu \mathrm{m} / \mathrm{hr}$; Aletta and Greene, 1988), Aplysia neurons on poly-L-lysine (5-25 $\mu \mathrm{m} / \mathrm{hr}$; Goldberg and Burmeister, 1986), and Xenopus retinal ganglion cell axons in vivo (16-52 $\mu \mathrm{m} / \mathrm{hr}$; Harris et al., 1987). For the pioneer growth cones, the different rates conferred by the 2 mechanisms of elongation would result in quite varied migration rates at different locations in the limb. The dependence of migration rate upon location has been noted for other growth cones monitored in situ: Xenopus retinal growth cones, for example, migrated at an average rate of $52 \mu \mathrm{m} / \mathrm{hr}$ in the optic tract, but at only 16 $\mu \mathrm{m} / \mathrm{hr}$ in the tectum (Harris et al., 1987).

In situ, we observed growth cone steering occurring through 3 mechanisms. First, veils may be selectively extended, or selectively expanded, between a subset of filopodia projected in different directions from the leading edge of the growth cone (Figs. 3A, 6A). This occurs most frequently where the growth cone is advancing along a broad, relatively homogeneous substrate, such as the distal region of the femur. In this case, the growth cone maintains its proximal course through the limb by selectively extending or expanding veils between more proximally directed filopodia.

Second, growth cone branches may form in 2 or more directions, and one of these branches may then be selected for further 
growth (Figs. 3C, 6B). This occurs in the limb most consistently where growth cones encounter the trochanter-coxa limb segment boundary. At this boundary, relatively high-affinity epithelial cells in the proximal end of the trochanter abut relatively low-affinity cells at the distal end of the coxa (Caudy and Bentley, 1986b, 1987; Condic and Bentley, 1989a). The initial response to this encounter is to cease proximal growth by extending new branches both dorsally and ventrally on the higher-affinity cells. This suggests that, compared to the cells in the distal region of the coxa, the dorsal and ventral boundary cells within the trochanter are similar in affinity. Subsequently, however, the pioneer growth cones always turn ventrally by withdrawing the dorsal branch. This process of steering by selective branch regression is very similar to the "micropruning" observed at defined substrate borders in vitro (Burmeister and Goldberg, 1988). Increased branching and subsequent branch loss at choice points has also been reported for many growth cones observed in situ (Tosney and Landmesser, 1985; Eisen et al., 1986; Holt, 1989; Myers et al., 1990).

Finally, at several locations, growth cones characteristically steer by selective dilation of a single filopodium oriented in a new direction (Figs. 3B, 4, 6C). As discussed above, the selected filopodium has contacted the surface of a high-affinity guidepost cell. A striking feature of these events is that this single filopodial contact can reorient an entire growth cone that has substantial branches and many filopodia extended in a different direction. Moreover, this process can occur while both filopodia and branches remain extended in the nonselected direction, as is also observed in branching in vitro (Burmeister and Goldberg, 1988). Therefore, the choice of direction does not appear to be mediated simply by the ability of filopodia or branches to remain extended in the selected versus nonselected direction. That the pioneer growth cones leave the segment boundary cells, to which they adhere strongly (Condic and Bentley, 1989a), after a single filopodial contact with the $\mathrm{Cx} 1$ cells suggests the involvement of mechanisms that can strongly amplify the effect of one adherent filopodium relative to other, also adherent, filopodia. Candidate mechanisms include selective effects on retrograde transport of actin filaments (Forscher and Smith, 1988), stretchactivated ion channels (Sigurdson and Morris, 1989), or reccptor-activated second-messenger systems (Bixby, 1989; Schuch et al., 1989). Generally, the presence of mechanisms in addition to adhesion is also suggested by the phenomenon of growth cone collapse during the maintenence of filopodial adhesions (Kapfhammer and Raper, 1987).

Steering by filopodial dilation implies that a signal generated by an interaction at the tip of a filopodium is transmilted to its base, where it can influence the influx of cytoplasmic material into its base. This is also suggested by selective elongation and possible steering of individual filopodia. The $\mathrm{Cx} 1$ guidepost cells extend radial filopodia in many directions around the cell body, but filopodia that have projected in certain circumferential or axial directions characteristically extend farther than those in other directions (Fig. 7C,D; Caudy and Bentley, 1986b). Selective elongation is also seen in "leading" filopodia protruded from pioncer growth cones migrating along longitudinal tracts in the CNS (Shankland, 1981) or limb segment boundaries (Caudy and Bentley, 1987). When pioneer growth cones encounter the trochanter-coxa segment boundary, individual filopodia are regularly observed that first extend proximally along the limb axis, then reorient circumferentially, in either the dorsal (Fig. $7 A$ ) or ventral (Fig. $7 B$ ) direction. These filopodia are sometimes aligned with filopodia extending from the $\mathrm{Cx} 1$ cells. A simple hypothesis is that both sets of filopodia have encountered a favorable substrate, interaction with which has activated a signal that promotes the selective influx of material into those filopodia resulting in their elongation.

\section{References}

Aletta JM, Greene LA (1988) Growth cone configuration and advance: a time-lapse study using video-enhanced differential interference contrast microscopy. J Neurosci 8:1425-1435.

Anderson H (1988) Drosophila adhesion molecules and neural development. Trends Neurosci 11:472-475.

Anderson H, Tucker RP (1988) Pioneer neurones use basal lamina as a substratum for outgrowth in the embryonic grasshopper limb. Development 104:601-608.

Argiro V, Bunge MB, Johnson MI (1984) Correlation between growth cone form and movement and their dependence on neuronal age. $J$ Neurosci 4:3051-3062.

Bate CM (1976) Pioneer neurones in an insect embryo. Nature 260: 54-56.

Bentley D, Caudy M (1983a) Navigational substrates for peripheral pioneer growth cones: limb-axis polarity cues, limb-segment boundaries, and guidepost neurons. Cold Spring Harbor Symp Quant Biol 48:573-585.

Bentley D, Caudy M (1983b) Pioneer axons lose directed growth after selective killing of guidepost cells. Nature 304:62-65.

Berlot J, Goodman CS (1984) Guidance of peripheral pioneer neurons in the grasshopper: adhesive hierarchy of epithelial and neuronal surfaces. Science 223:493-495.

Bieber AI, Snow PM, Hortsch M, Patel N, Jacobs JR, Traquina ZR, Schilling J, Goodman CS (1989) Drosophila neuroglian: a member of the immunoglobin superfamily with extensive homology to the vertebrate neural adhesion molecule L1. Cell 59:447-460.

Bixby JL (1989) Protein kinase C is involved in laminin stimulation of neurite outgrowth. Neuron 3:287-297.

Blair SS, Palka J (1989) Mosaic Drosophila wings reveal regional heterogeneity in the guidance of ectopic axons. J Neurobiol 20:55-68.

Blumberg B, MacKrell AJ, Olson PF, Kurkinen M, Monson J, Natzel JE, Fessler JH (1987) Basement membrane procollagen IV and its specialized carboxyl domain are conserved in Drosophila, mouse and human. J Biol Chem 262:5947-5950.

Bogaert T, Brown N, Wilcox M (1987) The Drosophila PS2 antigen is an invertebrate integrin that, like the fibronectin receptor, becomes localized to muscle attachments. Cell 51:929-940.

Braun J, Stent G (1989) Axon outgrowth along segmental nerves in the leech. I. Identification of candidate guidance cells. Dev Biol 132: $471-485$.

Bray D (1987) Growth cones: do they pull or are they pushed? Trends Neurosci 10:431-434.

Bray D, Chapman K (1985) Analysis of microspike movements on the neuronal growth cone. J Neurosci 5:3204-3213.

Burmeister DW, Goldberg DJ (1988) Micropruning: the mechanism of turning of Aplysia growth cones at substrate borders in vitro. J Neurosci 8:3151-3159.

Caudy M, Bentley D (1986a) Pioneer growth cone morphologies reveal proximal increases in substrate affinity within leg segments of grasshopper embryos. J Neurosci 6:364-379.

Caudy M, Bentley D (1986b) Pioneer growth cone steering along a series of neuronal and non-neuronal cues of different affinities. J Neurosci $6: 1781-1795$.

Caudy M, Bentley D (1987) Pioneer growth cone behavior at a differentiating limb segment boundary in the grasshopper embryo. Dev Biol 119:454-465.

Condic ML, Bentley D (1989a) Pioneer growth cone adhesion in vivo to boundary cells and neurons after enzymatic removal of basal lamina in grasshopper embryos. J Neurosci 9:2687-2696.

Condic ML, Bentley D (1989b) Pioneer neuron pathfinding from normal and ectopic locations in vivo after removal of the basal lamina. Neuron 3:427-439.

Denburg JL (1989) Developmental stage-specific antigens in the nervous system of the cockroach. Dev Biol 132:1-13.

Duerr IS, O'Connor TP, Bentley D (1989) Navigation decisions by pioneer neuron growth cones in vivo. Soc Neurosci Abstr 15:578.

Eisen JS, Myers PZ, Westerfield M (1986) Pathway selection by motor 
growth cones of identified motoneurones in live zebrafish embryos. Nature 320:269-271.

Elkins T, Hortsch M, Bieber A, Snow PM, Goodman CS (1990) Drosophila fasciclin I is a novel homophilic adhesion molecule that along with fasciclin III can mediate cell sorting. J Cell Biol 1 10:1825-1832.

Fessler JH, Fessler LI (1989) Drosophila extracellular matrix. Annu Rev Cell Biol 5:309-339.

Fessler LI, Campbell KG, Duncan KG, Fessler JH (1987) Drosophila laminin: characterization and localization. J Cell Biol 105:2383-2391.

Forscher P, Smith SJ (1988) Actions of cytochalasins on the organization of actin filaments and microtubules in a neuronal growth cone. J Cell Biol 107:1505-1516.

Goldberg DJ, Burmeister DW (1986) Stages in axon formation: observations of Aplysia axons in culture using video-enhanced contrastdifferential interference contrast microscopy. J Cell Biol 103:19211931.

Goldberg DJ, Burmeister DW (1989) Looking into growth cones. Trends Neurosci 12:503-506.

Grateios D, Naidet C, Astier M, Thiery JP, Semeriva M (1988) Drosophila fibronectin: a protein that shares properties similar to those of its mammalian homologue. EMBO J 7:215-223.

Gregory WA, Edmonson JC, Hatten ME, Mason CA (1988) Cytology and neuron-glial apposition of migrating cerebellar granule cells in vitro. J Neurosci 8:1728-1738.

Gundersen RW (1988) Interference reflection microscopic study of dorsal root growth cones on different substrates: assessment of growth cone-substrate contacts. J Neurosci Res 21:298-306.

Hammarback JA, Letourneau PC (1986) Neurite extension across regions of low cell-substratum adhesivity: implications for the guidepost hypothesis of axonal pathfinding. Dev Biol 117:655-662.

Harrelson AL, Goodman CS (1988) Growth cone guidance in insects: fasciclin II is a member of the immunoglobin superfamily. Science 242:700-707.

Harris WA, Holt CE, Bonhoeffer F (1987) Retinal axons with and without their somata, growing to and arborizing on the tectum of Xenopus embryos: a time-lapse video study of single fibres in vivo. Development 101:123-133.

Ho KK, Goodman CS (1982) Peripheral pathways are pioneered by an array of central and peripheral neurones in grasshopper embryos. Nature 297:404-406.

Holt CE (1989) A single-cell analysis of early retinal ganglion cell differentiation in Xenopus: from soma to axon tip. J Neurosci 9:31233145.

Honig M, Hume RI (1986) Fluorescent carbocyanine dyes allow living neurons of identified origin to be studied in long-term cultures. J Cell Biol 103:171-188.

Jan LY, Jan YN (1982) Antibodies to horseradish peroxidase as specific neuronal markers in Drosophila and grasshopper embryos. Proc Natl Acad Sci USA 79:2700-2704.

Kapfhammer JP, Raper JA (1987) Collapse of growth cone structure on contact with specific neurites in culture. J Neurosci 7:201-212.

Keshishian H, Bentley D (1983) Embryogenesis of peripheral nerve pathways in grasshopper legs. 1 . The initial nerve pathway to the CNS. Dev Biol 96:89-102.

Klambt C, Muller S, Lutzelschwab R, Rossa R, Totzke F, Schmidt O (1989) The Drosophila melanogaster l(2)gl gene encodes a protein homologous to the cadherin cell-adhesion molecule family. Dev Biol 133:425-437.
Kleitman N, Johnson MI (1989) Rapid growth cone translocation on laminin is supported by lamellipodial not filopodial structures. Cell Motil Cytoskel 13:228-300.

Lamoureux P, Buxbaum RE, Heideman SR (1989) Direct evidence that growth cones pull. Nature 340:159-162.

Lefcort F, Bentley D (1987) Pathfinding by pioneer neurons in isolated, opened and mesoderm-free limb buds of embryonic grasshoppers. Dev Biol 119:466-480.

Lefcort F, Bentley D (1989) Organization of cytoskeletal elements and organelles preceding growth cone emergence from an identified neuron in situ. J Cell Biol 108:1737-1749.

Letourneau PC (1975) Cell-to-substratum adhesion and guidance of axonal elongation. Dev Biol 44:92-101.

Letourneau PC (1979) Cell-substratum adhesion of neurite growth cones, and its role in neurite elongation. Exp Cell Res 124:127-138.

Letourneau P, Shattuck T, Ressler AH (1987) "Pull" and "push" in neurite elongation: observations on the effects of different concentrations of cytochalasin B and taxol. Cell Motil Cytoskel 8:193-209.

Mitchison T, Kirschner M (1988) Cytoskeletal dynamics and nerve growth. Neuron 1:761-772.

Montell DJ, Goodman CS (1988) Drosophila substratc adhcsion molecule: sequence of laminin B1 chain reveals domains of homology with mouse. Cell 53:463-473.

Myers C, Whitington PM, Ball EE (1990) Embryonic development of the innervation of the locust extensor tibiae muscle by identified neurons: formation and elimination of inappropriate axon branches. Dev Biol 137:194-206.

O'Connor TP, Duerr JS, Bentley D (1989) Saltatory extension of pioneer growth cones along single filopodia in vivo. Soc Neurosci Abstr $15: 1261$

O'Rourke NA, Fraser SE (1989) Gradual appearance of a regulated retinotectal projection pattern in Xenopus laevis. Dev Biol 132:251265.

Palka J (1986) Epithelial axon guidance in Drosophila. J Neurobiol 17:581-584.

Schuch U, Lohse MJ, Schachner M (1989) Neural cell adhesion molecules influence second messenger systems. Neuron 3:13-20.

Seeger MA, Haffley L, Kaufman TC (1988) Characterization of amalgam: a member of the immunoglobin superfamily from Drosophila. Cell 55:589-600.

Shankland M (1981) Development of a sensory afferent projection in the grasshopper embryo. I. Growth of peripheral pioneer axons within the central nervous system. J Embryol Exp Morphol 64:169-185.

Sigurdson WJ, Morris CE (1989) Stretch-activated ion channels in growth cones of snail neurons. J Neurosci 9:2801-2808.

Snow PM, Patel NH, Harrelson AH, Goodman CS (1987) Neuralspecific carbohydrate moiety shared by many glycoproteins in Drosophila and grasshopper embryos. J Neurosci 7:4137-4144.

Tosney KW, Landmesser LT (1985) Growth conc morphology and trajectory in the lumbosacral region of the chick embryo. J Neurosci 5:2345-2358.

Tosney KW, Wessells NK (1983) Neuronal motility: the ultrastructure of veils and microspikes correlates with their motile activities. J Cell Sci 61:389-411.

Zinn K, McAllister L, Goodman CS (1988) Sequence analysis and neuronal expression of fasciclin I in grasshopper and Drosophila. Cell 53:577-587. 